\title{
Comportamento da madeira a temperaturas elevadas
}

\author{
Wood behavior at high temperatures
}

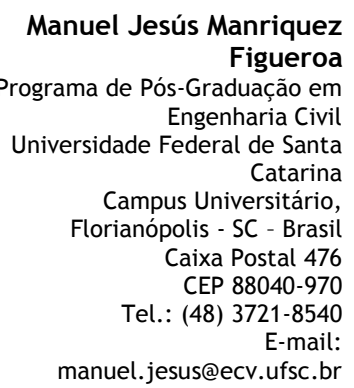

Poliana Dias de Moraes Programa de Pós-Graduação em Engenharia Civil Universidade Federal de Santa Catarina Tel.: (48) 3721-5175 E-mail: ecv1pdm@ecv.ufsc.br

Recebido em 24/07/09 Aceito em 05/11/09

\section{Manuel Jesús Manriquez Figueroa Poliana Dias de Moraes}

\section{Resumo \\ $\mathbf{N}$}

o Brasil, a combustibilidade da madeira e a insegurança diante de potenciais riscos relacionados a incêndios são consideradas restrições para a construção de edificações com sistemas estruturais em madeira. Essa situação é fruto do desconhecimento do comportamento da madeira em relação ao fogo. Nesse contexto, o objetivo deste trabalho é apresentar uma revisão bibliográfica abrangente sobre o comportamento da madeira a temperaturas elevadas, abordando assuntos relativos à degradação térmica, à taxa de carbonização e à influência da temperatura sobre as propriedades mecânicas da madeira. Essas informações podem contribuir para o aprimoramento de modelos numéricos sobre o comportamento termomecânico de estruturas de madeira em situação de incêndio, para a construção de edificações mais seguras e também para a eliminação do preconceito relativo ao uso desse material na construção civil.

Palavras-chave: Taxa de carbonização. Temperatura. Resistência Mecânica. Polímeros da Madeira.

\section{Abstract}

In Brazil, the combustibility of wood and insecurity regarding potential fire risks are considered restrictions for the use of timber-structured buildings. This situation is due to the lack of knowledge about the behavior of wood structures on fire. The aim of this study is to present a comprehensive literature review on the behavior of wood at high temperatures, discussing issues related to thermal degradation, charring rate and the influence of temperature on the mechanical properties of wood. This information may contribute to improve numerical models on the thermo-mechanical behavior of wood structures on fire, in order to build safer wooden buildings and also to eliminate preconceptions regarding the use of this material.

Keywords: Charring rate. Temperature. Mechanical strength. Wood polymers. 


\section{Introdução}

A madeira é um dos materiais de construção mais antigos e possui enormes potencialidades na indústria da construção. Ela tem bom desempenho quando aplicada em edifícios projetados, construídos e mantidos de forma adequada, porém seu uso como material de construção é limitado devido ao preconceito relativo a sua reação ao fogo. A madeira é um material combustível e, como os demais materiais combustíveis sólidos, quando aquecida, produz gases combustíveis que, quando expostos ao calor, queimam e produzem chama. Os gases quentes e as chamas, por sua vez, aquecem a porção de madeira ainda não atingida pelo calor e promovem a liberação de mais gases inflamáveis, gerando um processo em cadeia que alimenta a combustão.

A madeira, quando é submetida a uma situação de incêndio, irá queimar. Porém, tanto a madeira quanto o carvão oriundo da combustão da primeira são isolantes térmicos e retardam o fluxo de calor para o interior da seção, abrandando a velocidade da degradação térmica e retardando o avanço da frente de carbonização. Dessa forma, quando submetidos ao fogo, os elementos estruturais de madeira exibem em seus interiores, após a camada carbonizada, uma estreita camada aquecida, cujas propriedades mecânicas são afetadas pelo calor, e um núcleo inalterado.

Segundo White (2002), a resistência ao fogo de um elemento ou estrutura de madeira depende da existência de uma camada protetora ou espessura da camada carbonizada da madeira e das dimensões da seção residual, as quais dependem da taxa de carbonização da espécie de madeira usada.

No Brasil, a combustibilidade da madeira e a insegurança diante de potenciais riscos relacionados a incêndios são consideradas restrições para a construção de edificações com sistemas estruturais em madeira, as quais são agravadas pelo não-financiamento de construções dessa natureza pelas instituições bancárias nacionais. Essa situação é fruto do desconhecimento do comportamento da madeira em relação ao fogo. Na América do Norte e na Europa, o cenário é totalmente diferente. As construções em madeira são largamente utilizadas devido ao alto grau de industrialização e racionalização dos sistemas construtivos empregados, além do excelente empenho térmico exibido pela madeira e seus derivados.

As normas técnicas de construções em madeira apresentam os critérios de dimensionamento de estruturas em situação de incêndio. O Eurocódigo 5, Parte 1-2, (2002) prevê a utilização de métodos simplificados e avançados para a determinação da resistência dos elementos estruturais. Os métodos simplificados prescrevem a determinação da seção residual da madeira a partir da taxa de carbonização e também da redução das propriedades mecânicas do material em função da geometria da seção transversal. Já os métodos avançados permitem a modelagem dos fenômenos termomecânicos que ocorrem no interior da madeira. Para o uso de qualquer um dos métodos, faz-se necessário o conhecimento do comportamento da madeira a altas temperaturas.

Nesse contexto, o objetivo deste trabalho é apresentar uma revisão bibliográfica abrangente sobre o comportamento da madeira a temperaturas elevadas, abordando assuntos relativos à degradação térmica, à taxa de carbonização e à influência da temperatura sobre as propriedades mecânicas da madeira. Essas informações contribuirão para o desenvolvimento de projetos de edificação em madeira em situação de incêndio e, também, para diminuir o preconceito do uso desse material na construção civil.

Este trabalho encontra-se organizado na seguinte sequência: estrutura da madeira e elementos constituintes, degradação térmica da madeira, taxas de carbonização, influência da temperatura sobre os polímeros da madeira, influência da temperatura sobre as propriedades mecânicas da madeira e conclusões.

\section{Estrutura da madeira e elementos constituintes}

A madeira é um material heterogêneo e natural que possui diferentes tipos de células adaptadas a desempenharem funções específicas na árvore. Essas células são dispostas no sentido radial, tangencial e longitudinal, e ligadas entre si pela lignina, constituindo o tecido lenhoso. As variações físicas e anatômicas da madeira são grandes entre espécies e dentro da mesma espécie, principalmente em função da idade, de fatores genéticos e ambientais (BODIG; JAYNE, 1993).

Os principais polímeros que compõem a madeira são celulose, hemicelulose, lignina e extrativos em geral, cujas percentagens estão apresentadas na Tabela 1. A celulose compõe a maior parte dos tecidos vegetais, tanto em gimnospermas, quanto em angiospermas (WINANDY; ROWELL, 2005). A hemicelulose é um polissacarídeo que contém pelo menos dois tipos de monossacarídeos em sua estrutura primária, que podem corresponder a diferentes tipos de hexoses, pentoses e, em alguns 
casos, ácidos urônicos (FENGEL; WENEGER, 1984). Esses polissacarídeos estão associados com a celulose na parede celular e são constituídos por cadeias poliméricas menores que as da celulose, embora exerçam função estrutural análoga (FENGEL; WENEGER, 1984) de proporcionar suporte mecânico às fibras de celulose (WIKBERG; MAUNU, 2004). A lignina forma uma rede tridimensional com ligações cruzadas de vários tipos (SALMÉN, 1982), sendo a maior fonte de compostos aromáticos (FENGEL; WENEGER, 1984). Sua composição química, baseada em unidades fenilpropânicas, e sua estrutura macromolecular diferem significativamente da apresentada pela celulose e pela hemicelulose (WINANDY; ROWELL, 2005). Exerce a função de adesivo entre os diversos tecidos da madeira, dando-lhes rigidez e resistência (WINANDY; ROWELL, 2005).

Além dos polímeros citados, a madeira é impregnada por diversas substâncias conhecidas genericamente como extrativos. Essas substâncias são responsáveis por inúmeras características da madeira, embora sua atuação não esteja ainda bem determinada. Nas coníferas, predominam, em diferentes composições, as terebintinas, que são voláteis, e o breu, não volátil. Nas folhosas, a variedade de extrativos é bem maior, englobando compostos fenólicos, aromáticos, taninos, compostos nitrogenados e inúmeros carboidratos (FENGEL; WENEGER, 1984; WIKBERG; MAUNU, 2004; WINANDY; ROWELL, 2005).

Fonte: Winandy e Rowell (2005)

\begin{tabular}{c|c}
\hline Componentes & Presença \\
\hline Celulose & $40-45 \%$ \\
\hline Hemicelulose & $\approx 20 \%$ \\
\hline Lignina & $15-35 \%$ \\
\hline Outros constituintes & Até $10 \%$ \\
\hline
\end{tabular}

Tabela 1 - Composição química da madeira

\begin{tabular}{|c|l|}
\hline $\begin{array}{c}\text { Temperatura } \\
\left({ }^{\circ} \mathbf{C}\right)\end{array}$ & \multicolumn{1}{c|}{ Alterações na madeira } \\
\hline 55 & A estrutura natural da lignina é alterada. A hemicelulose começa a amolecer. \\
\hline 70 & Começa a retração transversal da madeira. \\
\hline 110 & A lignina lentamente começa a perder peso. \\
\hline 120 & $\begin{array}{l}\text { O teor de hemicelulose começa a diminuir e celulose alfa começa a aumentar. A } \\
\text { lignina começa a amolecer. }\end{array}$ \\
\hline 140 & A água de impregnação é liberada. \\
\hline 160 & A lignina se funde e começa a ressolidificar. \\
\hline 180 & $\begin{array}{l}\text { A hemicelulose começa a perder peso rapidamente depois de ter perdido 4\%. A } \\
\text { lignina da membrana de pontuação escoa. }\end{array}$ \\
\hline 200 & $\begin{array}{l}\text { A madeira começa perder peso rapidamente. As resinas fenólicas começam a se } \\
\text { formar e a celulose a se desidratar. }\end{array}$ \\
\hline 210 & $\begin{array}{l}\text { A lignina solidifica. A celulose amolece e despolimeriza-se. As reações } \\
\text { endotérmicas transformam-se em exotérmicas. }\end{array}$ \\
\hline 225 & A cristalinidade da celulose diminui e é retomada. \\
\hline 280 & A lignina atinge 10\% de perda de peso. A celulose começa a perder peso. \\
\hline 288 & Temperatura adotada para carbonização da madeira. \\
\hline 300 & O cerne amolece irrecuperavelmente. \\
\hline 320 & A hemicelulose é completamente degradada. \\
\hline 370 & A celulose apresenta perda de 83\% de seu peso inicial. \\
\hline 400 & A madeira é completamente carbonizada. \\
\hline
\end{tabular}

Fonte: Schaffer (1973)

Quadro 1 - Alterações provocadas termicamente na madeira seca em atmosfera inerte 
A madeira, por ser um polímero natural, quando submetida ao fogo, sofre despolimerização e carbonização, alterando suas propriedades mecânicas conforme o nível de temperatura e tempo de exposição ao calor ao qual foi submetida. Esse tema será tratado detalhadamente nas seções a seguir.

\section{Degradação térmica da madeira}

É fato conhecido que a madeira, assim como seus derivados, quando submetida à ação do calor, está sujeita a variações físico-químicas, como aquelas sintetizadas por Schaffer (1973) no Quadro 1. O gradiente térmico provocado pelo aquecimento diferencial do material induz a transferência de massa e, consequentemente, a secagem do material. Porém, quando as temperaturas forem elevadas, ocorrerá a despolimerização da madeira com liberação de gases voláteis inflamáveis ou não, a combustão do material lenhoso, a carbonização e a combustão incandescente do carbono fixo (BROWNE, 1958; WINANDY; ROWELL, 2005).

A combustão é a transformação térmica em presença de oxigênio ou ar, em quantidade suficiente para promover sua decomposição completa por uma fonte externa de calor. Quando esta transformação não tem o aporte suficiente de oxigênio, ou o aporte é controlado, ocorre a carbonização, cujo resíduo sólido é o carvão.

Vários trabalhos foram realizados sobre a degradação térmica da madeira, mostrando que o processo de decomposição e a temperatura na qual ela ocorre são dependentes, significativamente, da espécie da madeira (BODÎRLĂU; SPIRIDON; TEACĂ, 2007; PONCSÁK et al., 2006), dos anéis de crescimento (BODÎRLĂU et al., 2007) e do teor de umidade do material. As reações químicas no interior do material são complexas, com reações endotérmicas e exotérmicas ocorrendo simultaneamente tanto no tempo como no espaço.

Durante o aquecimento da madeira, muitos compostos orgânicos voláteis são produzidos e liberados, tais como álcoois, resinas, terpenos. São eles que participam na reação em cadeia durante o processo de combustão da madeira (MANNINEN; PASANEN; HOLOPAINEN, 2002). No início do aquecimento, quando a temperatura da madeira está acima de $100^{\circ} \mathrm{C}$, as ligações químicas de seus componentes começam a se romper. Entre $100{ }^{\circ} \mathrm{C}$ e $200^{\circ} \mathrm{C}$ há liberação de água, óxidos de carbono e vestígios de produtos biológicos (LEVAN, 1989; SHAFIZADEH, 1985).
Geralmente, o processo de degradação térmica é dividido em cinco fases, com suas respectivas faixas de temperaturas, conforme a Quadro 2. Os locais onde elas ocorrem são ilustrados pela Figura 1 (BABRAUSKAS, 2001, 2004; BROWNE, 1958; SARDINHA; WOLFANGO; VASCONCELOS, 2002; WHITE, 1990, 2006). As primeiras mudanças físico-químicas surgem a partir de $50{ }^{\circ} \mathrm{C}$ (SCHAFFER, 1973). As reações exotérmicas iniciam-se entre $150{ }^{\circ} \mathrm{C}$ e $160^{\circ} \mathrm{C}$ e aumentam com a elevação da temperatura. Acima de $200{ }^{\circ} \mathrm{C}$, esses fenômenos se refletem na perda acelerada de massa, a qual coincide com a redução da resistência mecânica da madeira decorrente do aumento da temperatura (PONCSÁK et al., 2006).

Os polímeros da madeira apresentam estabilidade térmica diferenciada em função da rede cristalina de cada um. A degradação térmica da celulose ocorre a temperaturas entre $200{ }^{\circ} \mathrm{C}$ e $280{ }^{\circ} \mathrm{C}$, com uma degradação progressiva que inclui despolimerização e desidratação. A temperaturas superiores a $280{ }^{\circ} \mathrm{C}$, ocorre uma rápida volatilização dos componentes químicos. Também foi observado que, quando a celulose é tratada termicamente, o teor de umidade retarda a sua degradação térmica (ROFFAEL; SCHALLER, 1971). A degradação térmica da hemicelulose ocorre entre $160{ }^{\circ} \mathrm{C}$ e $260{ }^{\circ} \mathrm{C}$ (FENGEL; WEGENER, 1984; SCHNIEWIND, 1985), sendo o primeiro carboidrato da madeira a se degradar, devido a sua estrutura heterogênea, à natureza não cristalina de sua estrutura e a seu baixo peso molecular em relação aos outros polímeros da madeira. Durante a degradação térmica da hemicelulose, a cristalinidade da celulose aumenta temporariamente e, segundo Kotilainen (2000) e Mangalam (2005), não há geração de gases combustíveis. A lignina é termicamente mais resistente que os demais carboidratos que compõem a madeira. Sua degradação térmica está situada entre $225^{\circ} \mathrm{C}$ e $450{ }^{\circ} \mathrm{C}$, com a presença de reações exotérmicas. Em torno de $200^{\circ} \mathrm{C}$, segundo Schniewind (1985), ocorrem reações de desidratação. Entre $150{ }^{\circ} \mathrm{C}$ e $300{ }^{\circ} \mathrm{C}$ ocorre o rompimento das ligações de carbono e, em torno de $300{ }^{\circ} \mathrm{C}$, as ligações laterais alifáticas começam a romper fora do anel aromático.

A degradação desses polímeros se reflete em perda de massa. Para taxa de aquecimento lenta e atmosfera inerte, a maior perda de massa da celulose ocorre entre $300{ }^{\circ} \mathrm{C}$ e $400{ }^{\circ} \mathrm{C}$, a da hemicelulose entre $250^{\circ} \mathrm{C}$ e $350^{\circ} \mathrm{C}$, e a da lignina entre $250{ }^{\circ} \mathrm{C}$ e $450{ }^{\circ} \mathrm{C}$ (ALÉ; KOTILAIMEN; ZAMAN, 2002). Até $600{ }^{\circ} \mathrm{C}$, a perda de massa alcança mais de $80 \%, 95 \%$ e $60 \%$ para a celulose, a hemicelulose e a lignina respectivamente. 


\begin{tabular}{|c|c|c|}
\hline Fase & Temperatura & Fenômeno \\
\hline $\mathrm{I}$ & Até $200^{\circ} \mathrm{C}$ & $\begin{array}{l}\text { - } \quad \text { Processo denominado pirólise lenta. } \\
\text { - } \quad \text { Liberação de vapor d'água e gases. } \\
\text { - } \quad \text { A madeira não se igniza. } \\
\text { - } \quad \text { Existência de algumas reações exotérmicas de oxidação. } \\
\text { - } \quad \text { Mudança de cor. }\end{array}$ \\
\hline II & 200 a $280^{\circ} \mathrm{C}$ & $\begin{array}{l}\text { - } \quad \text { Aumento de reação química e eliminação de gases. } \\
\text { - } \quad \text { Ocorrência de reações exotérmicas primárias sem inflamação. } \\
\text { - } \quad \text { Temperatura considerada como a temperatura de ignição. } \\
\text { - } \quad \text { Fase conhecida como pirólise rápida. }\end{array}$ \\
\hline III & 280 a $380^{\circ} \mathrm{C}$ & $\begin{array}{l}\text { - Produção de grandes quantidades de destilados, principalmente ácidos } \\
\text { acéticos e metanol. } \\
\text { - O resíduo final dessa fase já é carvão vegetal, mas que ainda } \\
\text { apresenta compostos volatilizáveis em sua estrutura. } \\
\text { - Fase exotérmica. }\end{array}$ \\
\hline IV & 380 a $500^{\circ} \mathrm{C}$ & $\begin{array}{l}\text { - } \text { Redução da emissão de gases. } \\
\text { - Produção de ácido acético, metanol, alcatrão e diversas substâncias } \\
\text { gasosas condensáveis. } \\
\text { - } \quad \text { A perda de massa é da ordem de } 70 \% \text { em relação à massa original. } \\
\text { - } \text { Fase exotérmica. }\end{array}$ \\
\hline V & Acima de $500^{\circ} \mathrm{C}$ & $\begin{array}{l}\text { - } \quad \text { Término da carbonização e início da gaseificação do carvão. } \\
\text { - } \quad \text { O carvão é o resíduo principal. } \\
\text { - } \quad \text { No interior da madeira permanece a temperatura das fases I, II e II. } \\
\text { - } \quad \text { Fase exotérmica. }\end{array}$ \\
\hline
\end{tabular}

Quadro 2 - Fases de degradação da madeira

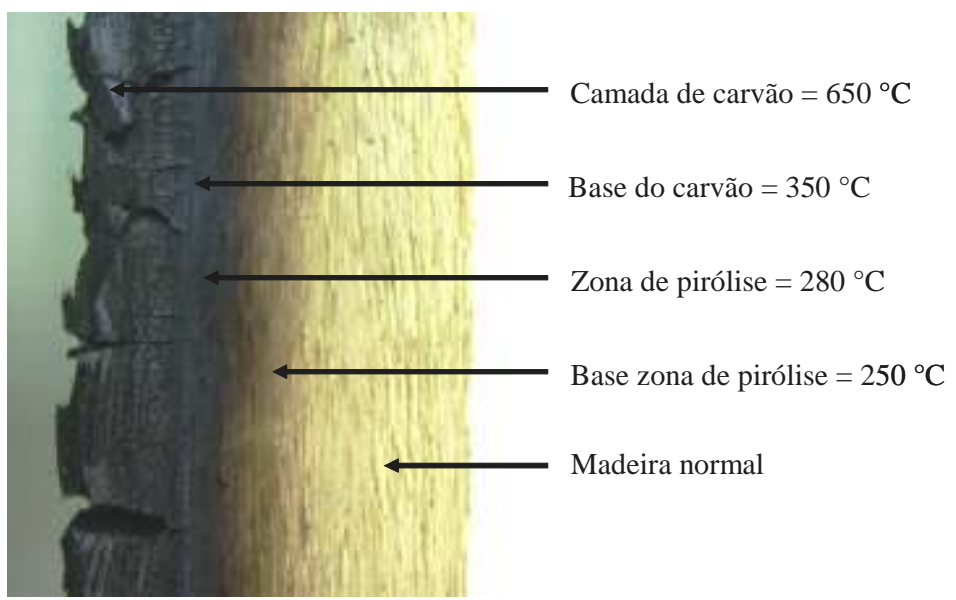

Figura 1 - Seção carbonizada de madeira

O conhecimento da perda de massa e das reações endotérmicas e exotérmicas em função da temperatura permite o aprimoramento de modelos numéricos avançados usados para a determinação do campo de temperatura em elementos de madeira submetidos ao fogo. Esses modelos podem considerar a variação da massa específica em função da temperatura e, também, as fontes de massa de geração de calor nas mesmas temperaturas que ocorrem as reações exotérmicas.

\section{Taxas de carbonização}

O carvão é um subproduto da combustão parcial da madeira, apresentando resistência mecânica desprezível. A taxa com a qual a madeira é convertida em carvão é denominada taxa de carbonização e serve para avaliar a resistência ao fogo de estruturas de madeira, visto que, de modo indireto, ela indica a redução da seção transversal dos elementos estruturais. Esse parâmetro, geralmente, é determinado por meio de testes de incêndio com elementos estruturais em tamanho real, nos quais a elevação da temperatura dos gases 
quentes segue as prescrições de curvas padrão de incêndio, tais como a das normas ISO 834 (1975) e ASTM E 119-08a (2009).

A temperatura de carbonização da madeira, para a determinação da taxa de carbonização para o cálculo estrutural em situação de incêndio, é um valor convencional para o qual não existe unanimidade até o momento. Na literatura, são encontrados valores entre $288^{\circ} \mathrm{C}$ e $360{ }^{\circ} \mathrm{C}$, sendo adotada pelo Eurocódigo 5, Parte 1-2, (2002) a temperatura de $300{ }^{\circ} \mathrm{C}$ como aquela de carbonização da madeira (BUCHANAN, 2001; COLLIER, 1992; LIE, 1977; NJANKOUO; DOTREPPE; FRANSSEN, 2004; SCHAFFER, 1967).

Existem vários fatores que influenciam a taxa de carbonização. Podem ser citados a massa específica, o teor de umidade, a espécie de madeira, as dimensões das peças de madeira, a forma da seção transversal e a intensidade do fluxo de calor (BUCHANAN, 2001; MIKKOLA, 1990; NJANKOUO; DOTREPPE; FRANSSEN, 2004; PINTO, 2005; SCHAFFER, 1967; WHITE, 1988). A massa específica afeta significativamente a taxa de carbonização. Quanto maior a massa específica da madeira, menor é a taxa de carbonização (MIKKOLA, 1990; NJANKOUO; DOTREPPE; FRANSSEN, 2004). O teor de umidade da madeira é um fator importante na taxa de carbonização, retardando o processo de combustão até a evaporação da água presente no material (SCHAFFER, 1967; WHITE, 1988; MIKKOLA, 1990; NJANKOUO; DOTREPPE; FRANSSEN, 2004). A influência desses dois parâmetros pode ser constatada pelo trabalho de Njankouo, Dotreppe e Franssen (2004). Eles determinaram a taxa de carbonização de espécies tropicais de folhosas com massa específicas entre 500 e 1.000 $\mathrm{kg} / \mathrm{m}^{3}$ e teor de umidade entre $9 \%$ e $20 \%$, de acordo com a curva de incêndio padrão da ISO 834 e temperatura convencional de carbonização de $300{ }^{\circ} \mathrm{C}$. Os valores obtidos estão situados entre 0,37 e $0,71 \mathrm{~mm} / \mathrm{min}$, conforme ilustra a Figura 2.

A influência do fluxo de calor sobre a taxa de carbonização é apresentada na Figura 3 podendo ser notada a não-linearidade do fenômeno (BUTLER ${ }^{1}, 1971$ apud DRYSDALE, 1998).

As dimensões e forma da seção transversal das peças de madeira também influenciam a taxa de carbonização. Para peças pequenas, a taxa de carbonização é maior que para peças grandes, visto que peças pequenas apresentam maior superfície específica que peças grandes. Segundo Buchanan (2001) e Pinto (2005), em peças de seção transversal retangular, a taxa de carbonização é maior do que em peças de seção circular, visto que existe maior área de exposição ao calor nas arestas do material. Eles também afirmam que a taxa de carbonização inicial é maior, estabilizando-se, após, em um valor constante, devido à camada protetora carbonizada oriunda do processo de combustão.

Segundo Schaffer (1967), White (1988) e Pinto (2005), assumir uma taxa constante de carbonização não é apropriado, principalmente para peças de dimensões pequenas, visto que os primeiros milímetros de carbonização podem representar uma porção significativa da seção transversal.

Alguns pesquisadores desenvolveram modelos de carbonização da madeira, considerando alguns dos fatores mencionados acima e seguindo a curva de incêndio padrão da norma americana ASTM E 119-08a (2009).

Schaffer (1967) propôs um modelo em função do teor de umidade e da massa específica para as espécies Pseudotsuga menziesii, Pinus spp e Quercus spp, dado pela Eq. 1 .

$t=C \cdot x_{c}$

onde $t$ é tempo, em min; $C$ é taxa de carbonização, em $\mathrm{min} / \mathrm{mm}$; e $x_{c}$ é espessura de madeira carbonizada, em mm. A taxa de carbonização (C) foi determinada considerando-se a temperatura convencional de carbonização de $288{ }^{\circ} \mathrm{C}$, resultando a Eq. 2 para o Pseudotsuga menziesii, a Eq. 3 para o Pinus spp e a Eq. 4 para o Quercus spp.

$$
\begin{aligned}
& C=(0,002269+0,00457 \mu) \rho+0,331 \\
& C=(0,000461+0,00095 \mu) \rho+1,016 \\
& C=(0,001583+0,00318 \mu) \rho+0,594
\end{aligned}
$$

nas quais $\mu$ é o teor de umidade, em \%, e $\rho$ é a massa específica da madeira, em $\mathrm{kg} / \mathrm{m}^{3}$.

${ }^{1}$ BUTLER, C.P. Notes on Charring Rates in Wood. Fire Research Note, Borehamwood, n. 896, 1971. 


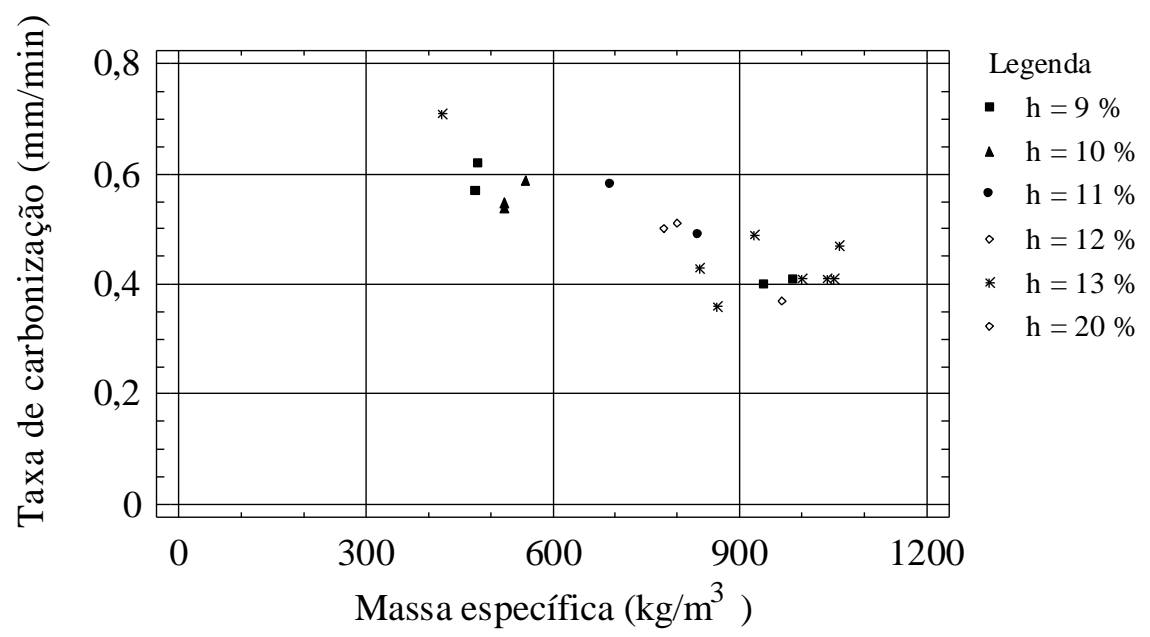

Fonte: Njankouo, Dotreppe e Franssen (2004)

Figura 2 - Taxa de carbonização

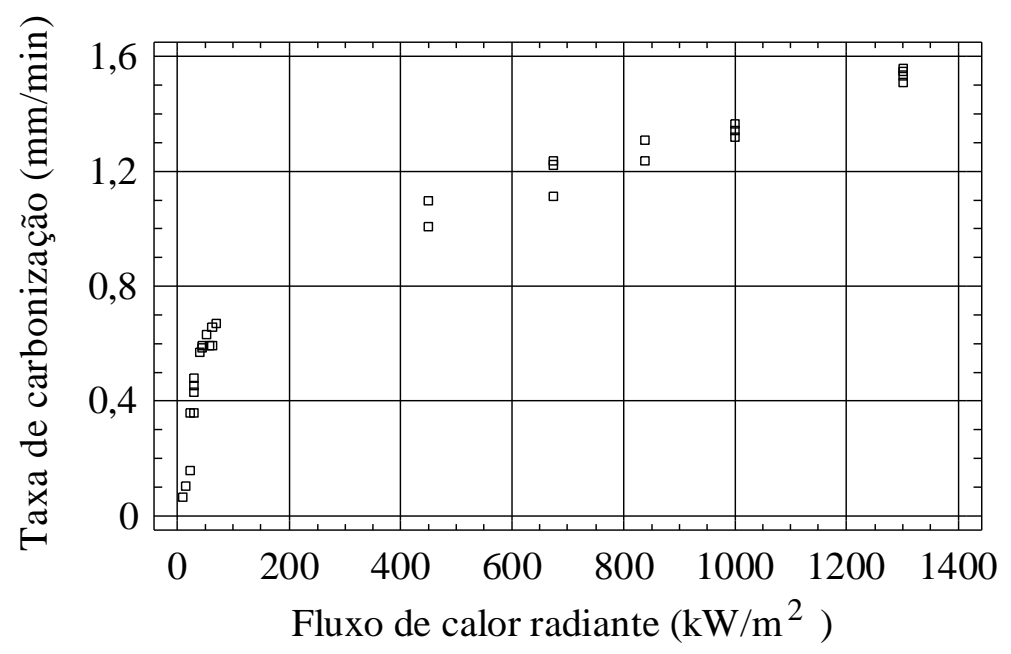

Fonte: Butler (1971) ${ }^{2}$ apud Drysdale (1998)

Figura 3 - Taxa de carbonização

O modelo proposto por White (1988), para peças de grandes dimensões, foi baseado em 8 espécies de madeiras, sendo 4 coníferas (Southem pine, Westem red cedar, Redwood, Engelman spruce) e 4 folhosas (Basswood, Hard maple, Red oak, Yellow popla) (Tabela 2) e é dado pela Eq. 5. Nesse modelo, a taxa de carbonização foi determinada em função da massa específica anidra, do teor de umidade e do fator de contração do carvão, adotando-se a temperatura de $288^{\circ} \mathrm{C}$ para a carbonização da madeira.

$t=m x^{1,23}$

$m=-0,147+0,000564 \rho+1,21 \mu+0,53202 f_{c}$

\footnotetext{
${ }^{2}$ BUTLER, C.P. Notes on Charring Rates in Wood. Fire Research Note,
} Borehamwood, n. 896, 1971.

onde $m$ é a taxa de carbonização, em $\mathrm{min} / \mathrm{mm}^{1,23} ; \rho$ é a densidade anidra; e $f_{c}$ é o fator de contração do carvão.

Lie (1977) propõe valores de $0,40 \mathrm{~mm} / \mathrm{min}$, de $0,60 \mathrm{~mm} / \mathrm{min}$ e de $0,80 \mathrm{~mm} / \mathrm{min}$ para folhosas úmidas, coníferas de densidade média e madeiras leves e secas respectivamente. Contudo, para madeira serrada e madeira laminada colada (MLC) de uso estrutural, o autor propõe o valor de 0,635 $\mathrm{mm} / \mathrm{min}$.

Collier (1992) constatou que a suposição de uma taxa de carbonização de $0,60 \mathrm{~mm} / \mathrm{min}$ é válida somente para madeiras com massa específica superior a $600 \mathrm{~kg} / \mathrm{m}^{3}$ e teor de umidade de $12 \%$, e que a determinação da taxa de carbonização 
baseada na densidade da madeira seria mais confiável, especialmente para madeiras de menor densidade.

Buchanan (2001) propõe uma taxa nominal de carbonização de $0,65 \mathrm{~mm} / \mathrm{min}$, resultado confirmado para estrutura pesada de grande seção. Para espécies cultivadas no Brasil, existem poucos resultados na literatura. Pinto (2005) apresenta valores de taxa de carbonização para a espécie Eucalyptus citriodora e Eucalyptus grandis, para teor de umidade aproximado de $24 \%$ e massa específica de 1.060 e $880 \mathrm{~kg} / \mathrm{m}^{3}$ respectivamente. Os ensaios foram realizados em peças estruturais com exposição ao fogo em 4 faces, obtendo valores de $0,58 \mathrm{~mm} / \mathrm{min}$ para ambas as espécies. Landesmann et al. (2008) obtiveram, em ensaios com painel radiante, valores de taxa de carbonização de $0,81 \mathrm{~mm} / \mathrm{min}$ para Schizolobium amazonicum com massa específica de $365 \mathrm{~kg} / \mathrm{m}^{3}$ e $12 \%$ teor de umidade.

Os valores de taxa de carbonização encontrados na literatura estão reunidos na Tabela 2. Verifica-se que eles variam de acordo com a espécie, a massa específica, o teor de umidade e a natureza do elemento de madeira.

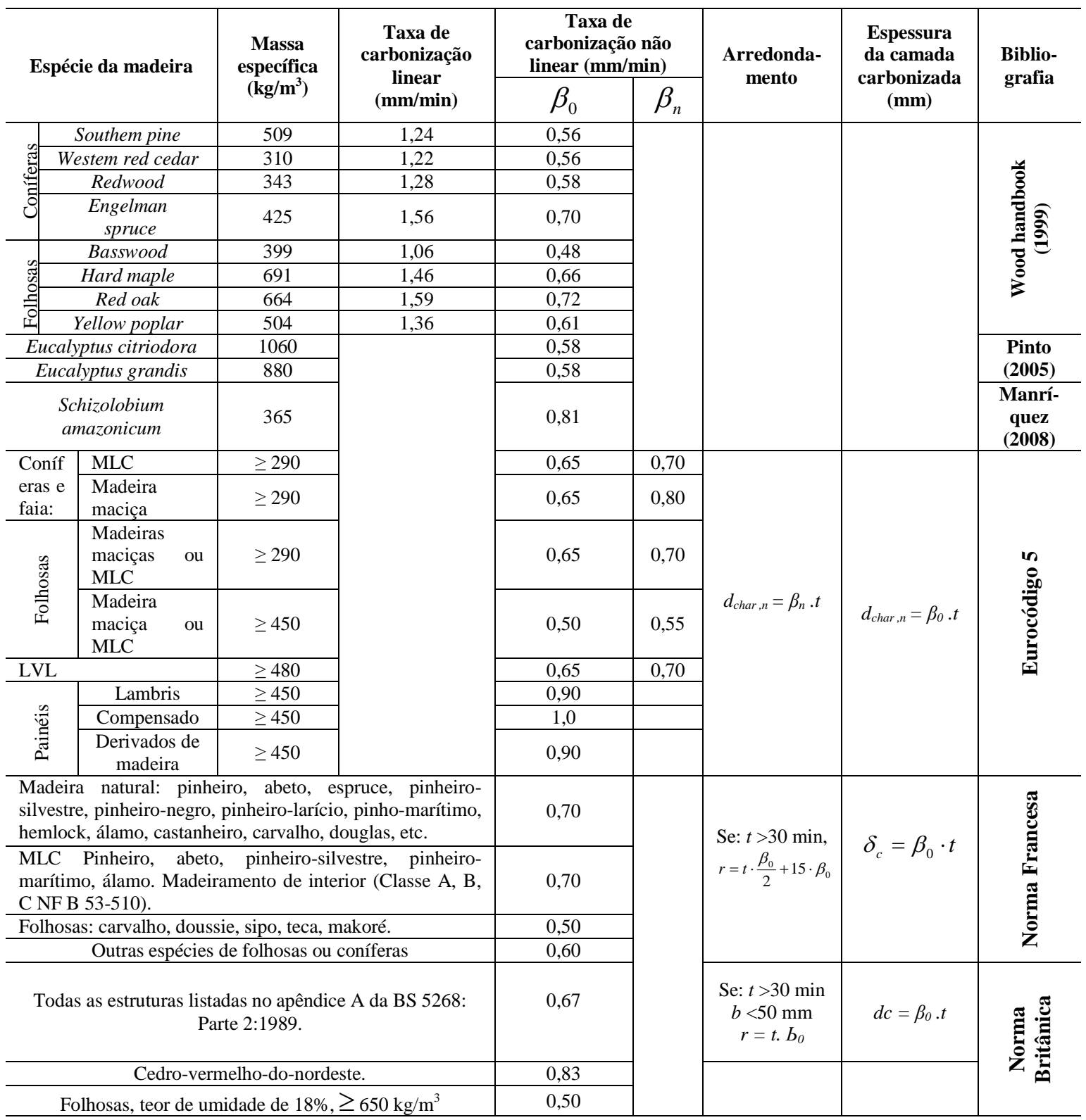

Tabela 2 - Taxas de carbonização 


\section{Influência da temperatura sobre os polímeros da madeira}

Vários trabalhos foram realizados sobre a influência da temperatura nos polímeros da madeira, principalmente sobre seu amolecimento, o qual é caracterizado pela temperatura de transição vítrea (BACK; SALMÉN, 1982; BHUIYAN; HIRAI; SOBUE, 2000; FENGEL, 1967; FENGEL; WEGENER, 1984; GORING, 1963; HATAKEYAMA; HATAKEYAMA; NAKANO, 1974; IRVINE, 1984; MANGALAM, 2005; ZERONIAN, MENEFEE, 1976; PONCSÁK et al., 2006; SALMÉN, 1982; SCHAFFER, 1973; SIVONEN et al., 2002; YANO; HATAKEYAMA; HATAKEYAMA, $1976 ; \quad$ YILDIZ; GÜMÜSKAYA，2007; OLSSON; SALMÉN, 1997). A transição vítrea é a passagem de um estado desordenado rígido (vítreo) do polímero para um estado desordenado maior, no qual as cadeias poliméricas possuem uma maior mobilidade. Essa mobilidade, no caso de algumas classes de polímeros naturais como a hemicelulose, a celulose e a lignina, dá origem a um comportamento menos rígido.

A lignina e a hemicelulose são polímeros amorfos e essencialmente termoplásticos para os quais o principal ponto de amolecimento é aquele da transição vítrea. As transições vítreas da madeira estão ligadas à temperatura, ao teor de umidade, ao peso molecular do polímero, à natureza do material, se ele está em sua forma isolada ou se está na forma de madeira, na forma cristalina ou amorfa.

A transição vítrea a seco dos polímeros da madeira ocorre preferencialmente a altas temperaturas, quando a taxa de degradação dos polímeros é significativa. Para a celulose, a temperatura de transição situa-se entre $200{ }^{\circ} \mathrm{C}$ e $250{ }^{\circ} \mathrm{C}$. Para as hemiceluloses, a transição vítrea é observada na faixa de $150{ }^{\circ} \mathrm{C}$ a $220^{\circ} \mathrm{C}$. Segundo Salmén (1982), a amplitude da faixa de temperatura é, em parte, devida a diferenças na composição química e no teor de umidade e à existência de grupos flexíveis que reduzem o empacotamento das fibras do polímero. Para a lignina in situ, a transição vítrea ocorre a temperaturas superiores a $205^{\circ} \mathrm{C}$ (BACK; SALMÉN, 1982) e é influenciada pelo peso molecular do polímero, em decorrência do aumento do grau de ligações cruzadas (GORING, 1963; ZERONIAN; MENEFEE, 1976). Quando o teor de umidade aumenta, a temperatura da transição vítrea se desloca na direção das temperaturas inferiores, tendendo a uma temperatura-limite, na qual a umidade não exerce um efeito significativo. Para várias espécies, a transição vítrea da lignina in situ, no ponto de saturação das fibras, ocorre em zona compreendida entre $60{ }^{\circ} \mathrm{C}$ e $90{ }^{\circ} \mathrm{C}$ (IRVINE, 1984).

$\mathrm{O}$ amolecimento dos polímeros é acompanhado de mudanças importantes nas propriedades mecânicas do material, principalmente do módulo de elasticidade (BACK; SALMÉN, 1982; IRVINE, 1984), influindo no desempenho mecânico da madeira.

\section{Influência da temperatura sobre as propriedades mecânicas da madeira}

Vários trabalhos foram realizados para determinar a influência da temperatura sobre as propriedades mecânicas da madeira submetida a altas temperaturas (GERHARDS, 1982; GREEN; WINANDY; KRETSCHMANN, 1999; KNUDSON; $\quad$ SCHNIEWIND, 1975; KOLLMANN; CÔTÉ, 1968 LAU; BARRET, 1979; MANRÍQUEZ, 2008; MORAES, 2003; MORAES; ROGAUME; TRIBOULOT, 2005; NYMAN, 1980; OHSAWA; YONEDA, 1978; OSTMAN, 1985; PESCADOR, 2008; PREUSSER, 1968; SANO, 1961; SCHAFFER, 1967, 1973, 1986). Essa influência pode se manifestar por meio de efeitos temporários e efeitos permanentes, os quais dependem do grau de degradação do material causado pela exposição ao calor e pela temperatura.

Os efeitos permanentes não desaparecem depois do resfriamento da madeira e ocorrem a temperaturas superiores a $65^{\circ} \mathrm{C}$, sem perda significativa de peso dos carboidratos. Dependem da temperatura e do teor de umidade da madeira e são oriundos, provavelmente, das reações de despolimerização, nas quais a ruptura das ligações químicas começa a ocorrer a temperaturas superiores a $100{ }^{\circ} \mathrm{C}$. Os efeitos permanentes se manifestam pela perda do peso dos carboidratos, perda de água de adesão e pelo amolecimento da lignina (ATREYA, 1983; BRYDEN, 1998; BROWNE, 1958; MILLER; BELLAN, 1996; SHAFIZADEH, 1985) e refletem diretamente nas propriedades mecânicas da madeira.

A seguir, são apresentados os resultados relativos à influência da temperatura sobre a resistência à compressão, à tração, ao cisalhamento, ao embutimento paralelo e perpendicular às fibras, ao arrancamento de pregos e ao módulo de elasticidade à compressão e à flexão, normalizados em relação àqueles obtidos à temperatura ambiente. 


\section{Resistência à compressão paralela às fibras}

A Figura 4 ilustra os resultados obtidos por Schaffer (1973) e Knudson e Schniewind (1975), para a espécie Pseudotsuga menziesii, e por Manríquez (2008), para a espécie Schizolobium amazonicum. Knudson e Schniewind (1975) utilizaram amostras com teor de umidade de $12 \%$ e corpos-de-prova de $0,48 \mathrm{~cm} \times 0,48 \mathrm{~cm} \times 1,90 \mathrm{~cm}$ Os resultados apresentados por Schaffer (1973) são superiores aos obtidos por Manríquez (2008) na faixa de $25{ }^{\circ} \mathrm{C}$ a $50{ }^{\circ} \mathrm{C}$. Essa diferença pode estar associada ao teor de umidade das amostras. A utilizada por Schaffer (1973) apresenta teor de umidade de $0 \%$, enquanto a de Manriquez (2008) apresenta $10 \%$. A partir de $140{ }^{\circ} \mathrm{C}$ os resultados apresentados por Schaffer (1973) são inferiores aos dos outros autores, provavelmente devido ao teor de umidade zero dos corpos-de-prova desse pesquisador ter permitido uma degradação mais rápida dos polímeros da madeira, refletindo-se na perda de resistência.

\section{Resistência à tração paralela às fibras}

A Figura 5 exibe os resultados de Schaffer (1973), Knudson e Schniewind (1975), Lau e Barrett (1979), Ostman (1985) e Manríquez (2008). Schaffer (1973) e Knudson e Schniewind (1975) estudaram a espécie Pseudotsuga menziesii. Porém, Schaffer (1973) empregou amostra com massa específica entre 432 e $522 \mathrm{~kg} / \mathrm{m}^{3}$, teor de umidade $0 \%$ e corpos-de-prova de $3,2 \mathrm{~mm}$ de espessura e 25,4 $\mathrm{mm}$ de largura, enquanto Knudson e Schniewind (1975) utilizaram amostra com massa específica entre 420 e $570 \mathrm{~kg} / \mathrm{m}^{3}, 12 \%$ de teor de umidade e corpos-de-prova com seção transversal de $48 \mathrm{~mm}$. Lau e Barrett (1979) realizaram ensaios com amostra de Pinus sylvestris de massa específica entre 500 e $590 \mathrm{~kg} / \mathrm{m}^{3}$, teor de umidade entre $7 \%$ e $11 \%$, com corpos-de-prova de $90 \mathrm{~mm}$ por $35 \mathrm{~mm}$. Ostman (1985) estudou o abeto vermelho com teor de umidade de $12 \%$ e massa específica entre 400 e $490 \mathrm{~kg} / \mathrm{m}^{3}$, com corpos-deprova de $1 \mathrm{~mm}$ por $10 \mathrm{~mm}$ de seção transversal. Manríquez (2008) estudou o Schizolobium amazonicum com teor de umidade de $12 \%$ e massa específica entre 283 e $443 \mathrm{~kg} / \mathrm{m}^{3}$ e corpos-deprova de $5 \mathrm{~mm}$ por $20 \mathrm{~mm}$ de seção transversal. aquecidos superficial, por placas quentes entre 5 min a 20 min. Manríquez (2008) utilizou amostras com umidade de $12 \%$ e corpos-de-prova de $5 \mathrm{~cm} \times$ $5 \mathrm{~cm} \times 15 \mathrm{~cm}$ aquecidos no forno elétrico durante 180 min. Os resultados obtidos por ambos os pesquisadores foram similares, detectando diferenças apenas na temperatura em torno de 150 ${ }^{\circ} \mathrm{C}$. Esse fenômeno pode estar associado ao tamanho dos corpos-de-prova e ao modo como eles foram aquecidos.

Os resultados obtidos por Schaffer (1973) são superiores àqueles apresentados pelos outros autores, devido, provavelmente, ao teor de umidade inicial dos corpos-de-prova utilizados por ele. Observa-se que a tendência dos resultados obtidos por Knudson e Schniewind (1975), Lau e Barrett (1979) e Ostman (1985) são similares, embora as características físicas e anatômicas das espécies estudadas sejam diferentes. Os resultados obtidos por Manríquez (2008) chamam a atenção por apresentarem valores médios que diferem consideravelmente dos demais.

\section{Resistência ao cisalhamento}

Na Figura 6 são apresentados os resultados obtidos por Ohsawa e Yoneda (1978) para amostras úmidas, por Sano (1961) para amostras secas, ambos apresentados por Gerhards (1982) e por Manríquez (2008) com $12 \%$ de teor de umidade à temperatura ambiente.

Os resultados obtidos por Manríquez (2008) permanecem praticamente constantes entre $20^{\circ} \mathrm{C}$ e $90{ }^{\circ} \mathrm{C}$, diferindo consideravelmente daqueles obtidos na literatura. Essa diferença, provavelmente, está relacionada com o teor de umidade no momento do ensaio e com a metodologia empregada. $\mathrm{O}$ teor de umidade dos corpos-de-prova de Manríquez (2008) era de $12 \%$ a $20^{\circ} \mathrm{C}$ e estavam praticamente anidros a $100{ }^{\circ} \mathrm{C}$. $\mathrm{O}$ modelo de corpo-de-prova utilizado por Manríquez (2008) era o proposto Szücs et al. (1998), enquanto o dos outros autores era o da norma ASTM.

A tendência dos resultados apresentados por Sano (1961), oriundos de amostras secas, é similar à tendência dos resultados obtidos por Manríquez (2008) entre $100{ }^{\circ} \mathrm{C}$ e $230{ }^{\circ} \mathrm{C}$, quando as amostras desse último estavam com baixo teor de umidade ou praticamente anidras. 


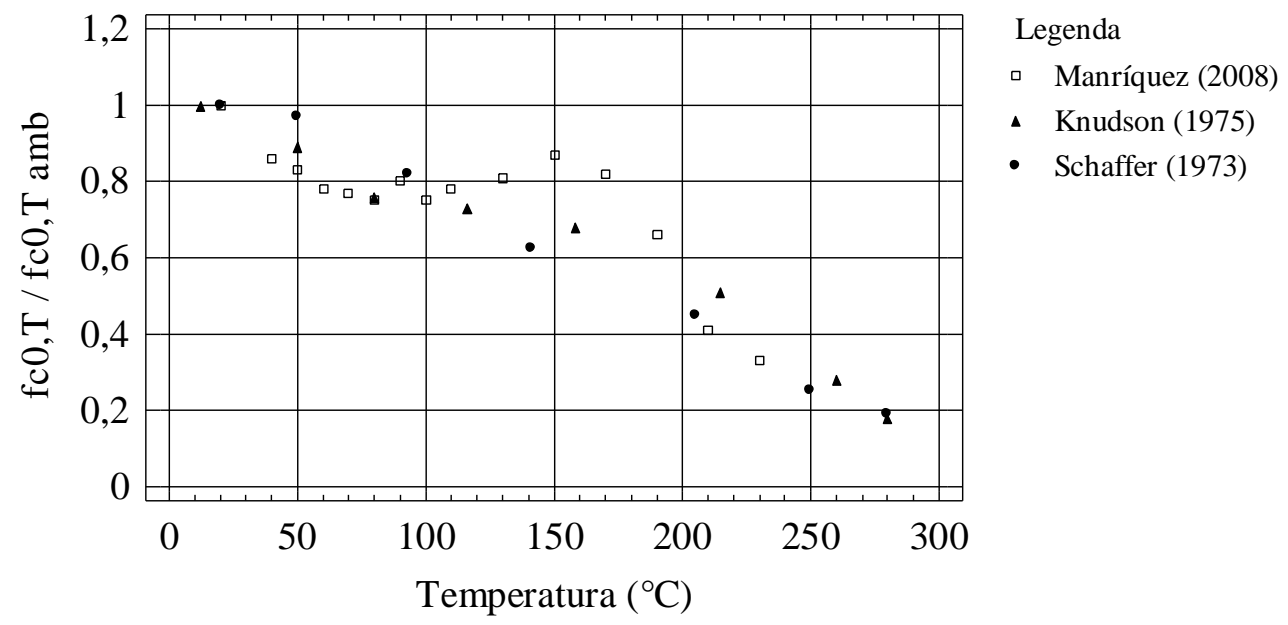

Figura 4 - Compressão paralela às fibras relativa

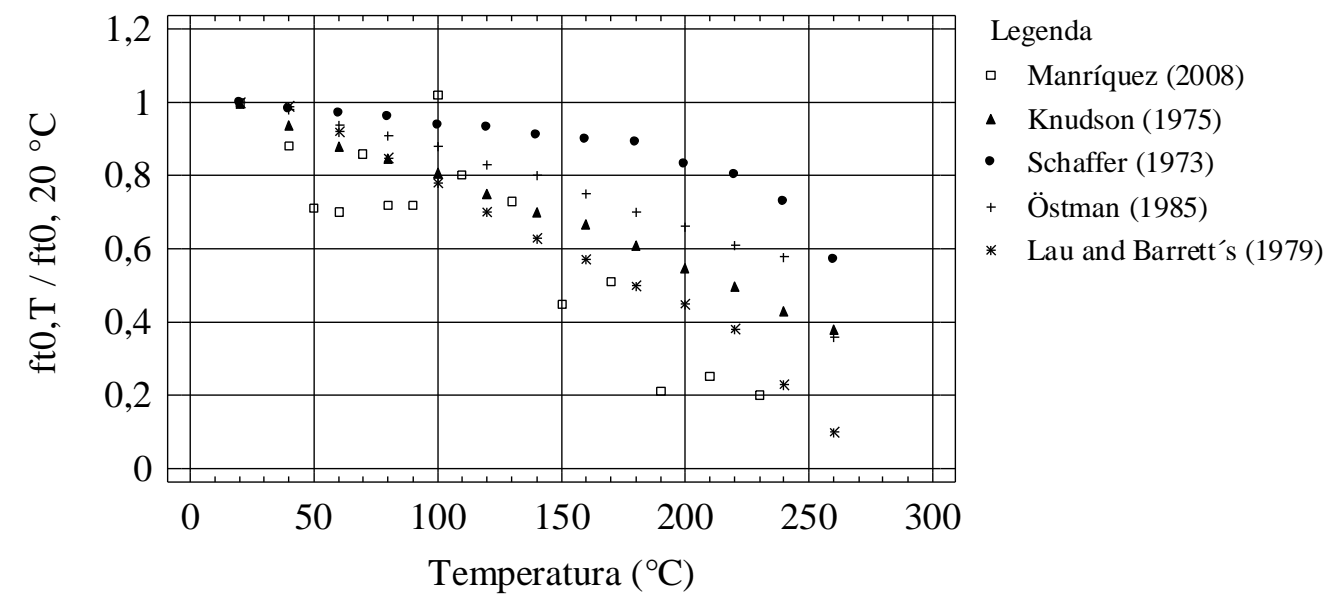

Figura 5 - Resistência ao cisalhamento paralelo às fibras relativa

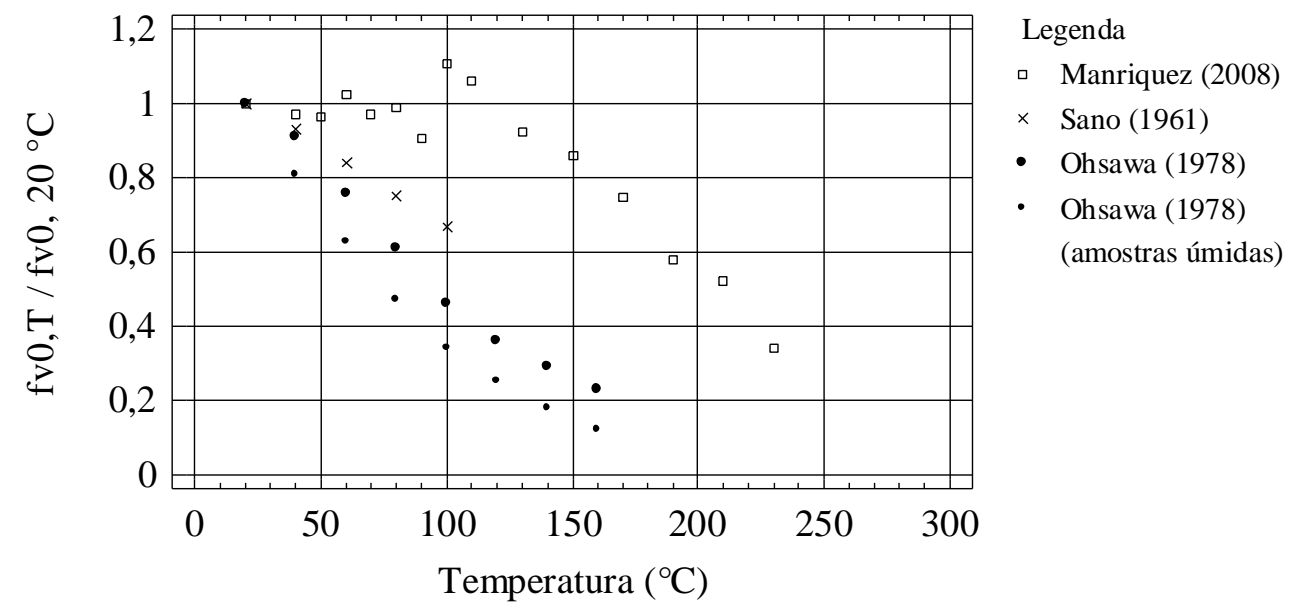

Figura 6 - Resistência ao embutimento paralelo às fibras relativa 


\section{Resistência ao embutimento paralelo e perpendicular às fibras}

As Figuras 7 e 8 apresentam os resultados obtidos por Moraes et al. (2005) e Manriquez (2008) para o embutimento paralelo $\left(f_{e, 0}\right)$ e perpendicular $\left(f_{e, 90}\right)$ às fibras respectivamente. Moraes, Rogaume $\mathrm{e}$ Triboulot (2005) utilizaram amostras de Pinus sylvestris com teor de umidade de $11 \%$ e massa específica entre 489 e $680 \mathrm{~kg} / \mathrm{m}^{3}$, enquanto Manríquez (2008) utilizou amostras de Schizolobium amazonicum com teor de umidade de $12 \%$ e massa específica entre 303 e $454 \mathrm{~kg} / \mathrm{m}^{3}$. As dimensões dos corpos-de-prova de ambos as pesquisas eram de $2,5 \mathrm{~cm} \times 6,0 \mathrm{~cm} \times 14,0 \mathrm{~cm}$.

Os resultados obtidos por Manríquez (2008) são similares aos obtidos por Moraes, Rogaume e
Triboulot (2005) para embutimento paralelo às fibras $\left(f_{e, 0}\right)$. Para o embutimento perpendicular $\left(f_{e, 90}\right)$, as diferenças entre os resultados dos dois estudos são maiores. Elas podem estar associadas às características anatômicas das espécies utilizadas. A espécie estudada por Moraes, Rogaume e Triboulot (2005) é uma conífera, enquanto a estudada por Manríquez (2008) é uma folhosa.

Percebe-se que, para os embutimentos paralelo e perpendicular, a redução dos valores não é monotônica, apresentando um mínimo relativo de aproximadamente $25 \%$ a $80{ }^{\circ} \mathrm{C}$. A $240{ }^{\circ} \mathrm{C}$, essa redução chega a quase $60 \%$. Os pesquisadores verificaram que o teor de umidade e a temperatura influem consideravelmente na resistência ao embutimento da madeira.

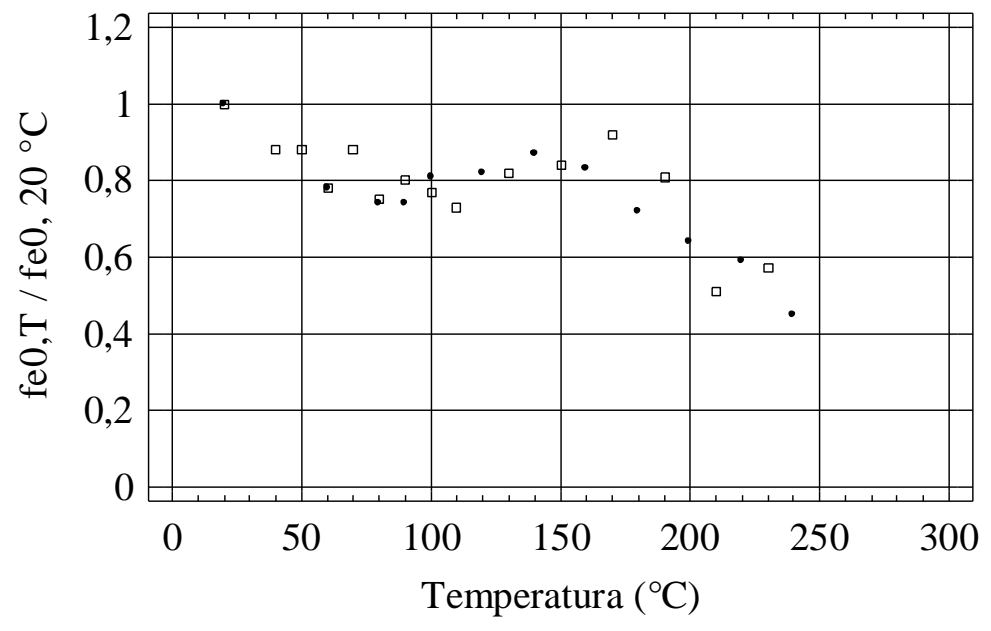

Legenda

- Manríquez (2008)

- Moraes (2005)

Figura 7 - Resistência ao embutimento paralelo às fibras relativo

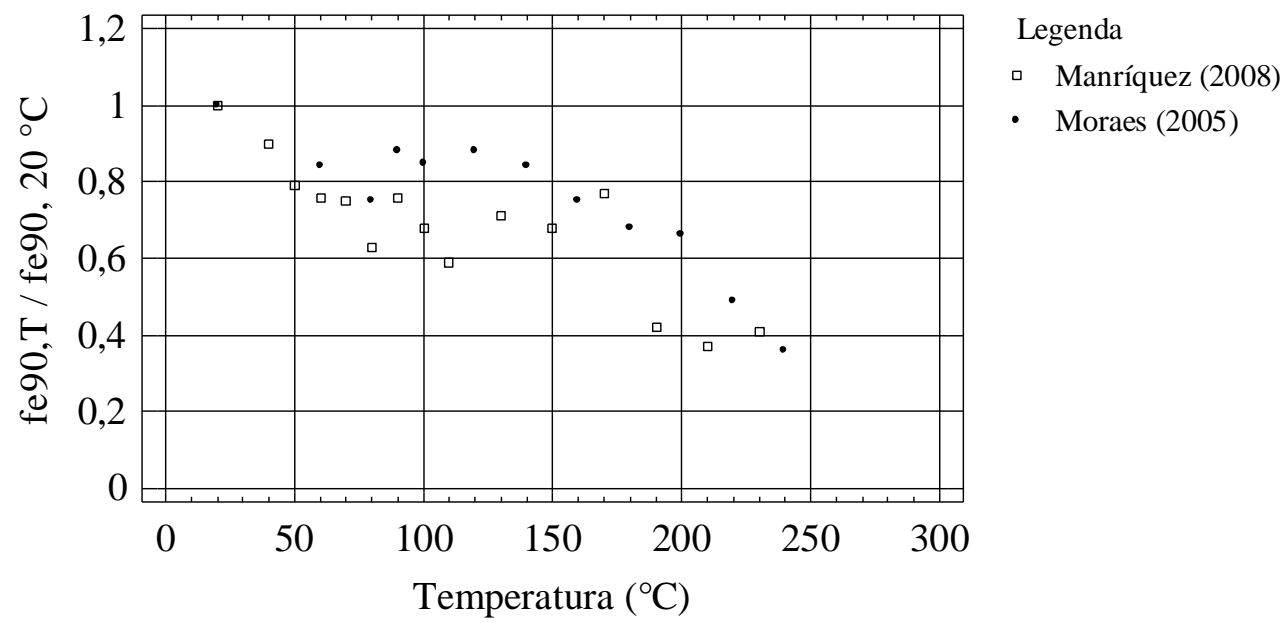

Figura 8 - Resistência ao embutimento perpendicular às fibras relativo 


\section{Resistência ao arrancamento de pregos}

A Figura 9 apresenta os resultados de resistência ao arrancamento normalizada obtidos por Pescador, Manríquez e Moraes (2008). Eles realizaram ensaios de arrancamento, segundo a norma chilena NCh 979 (1986), para 15 níveis de temperatura entre $20^{\circ} \mathrm{C}$ e $230^{\circ} \mathrm{C}$, com amostras de Schizolobium amazonicum com umidade de $12 \%$ e massa específica situada entre 342 e $511 \mathrm{~kg} / \mathrm{m}^{3}$. Os corpos-de-prova eram de $5 \mathrm{~cm} \times 5 \mathrm{~cm} \times 15 \mathrm{~cm} \mathrm{e}$ os pregos de aço com diâmetro de $3,2 \mathrm{~mm}$ e comprimento de $65 \mathrm{~mm}$, cravados a uma profundidade de $45 \mathrm{~mm}$.

Observou-se que, em temperaturas relativamente baixas, entre $50{ }^{\circ} \mathrm{C}$ e $60{ }^{\circ} \mathrm{C}$, a resistência média ao arrancamento nas três direções anatômicas da madeira apresenta uma redução entre $20 \%$ e $30 \%$ da resistência à temperatura ambiente. A $150^{\circ} \mathrm{C}$, a redução é máxima, situando-se entre $70 \%$ e $80 \%$.

\section{Módulo de elasticidade à compressão paralelo às fibras}

A Figura 10 apresenta valores do módulo de elasticidade à compressão paralela às fibras normalizado, obtidos por Preusser (1968), Schaffer (1973), Nyman (1980) e Ostman (1985). Os resultados mostram que o efeito da temperatura sobre o módulo de elasticidade apresenta um comportamento aproximadamente linear até 180 ${ }^{\circ} \mathrm{C}$. Preusser (1968 apud GERHARDS, 1982) mostra valores próximos a zero para uma temperatura de $250{ }^{\circ} \mathrm{C}$, enquanto os resultados apresentados por outros autores ainda têm uma porcentagem entre $50 \%$ e $70 \%$ do módulo da elasticidade relativo.

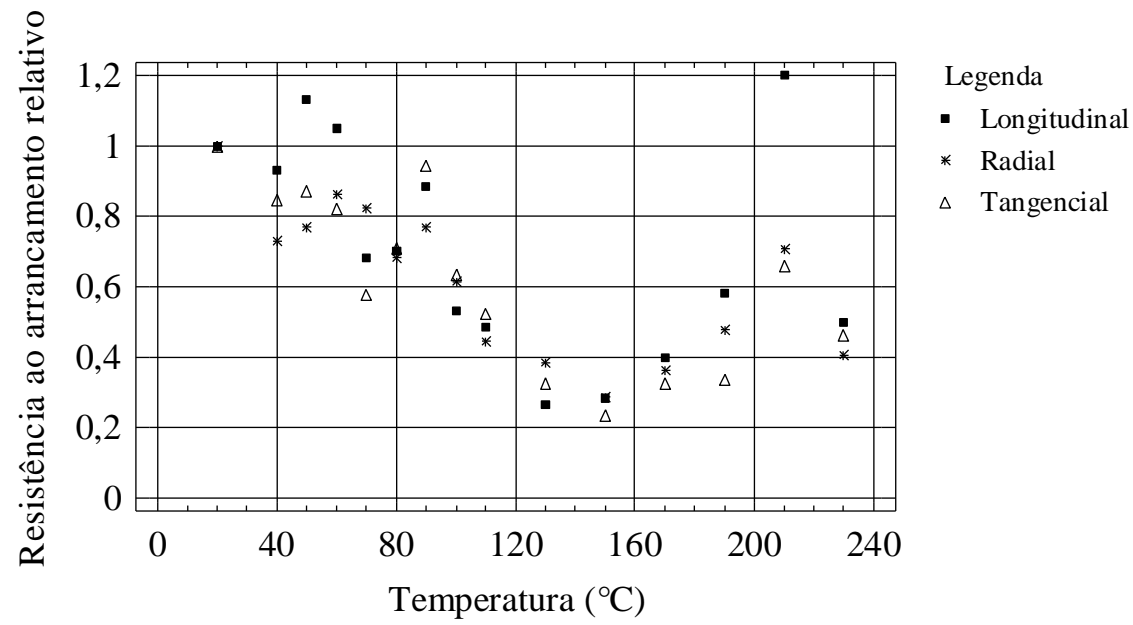

Fonte: Pescador (2008)

Figura 9 - Resistência ao arrancamento relativo

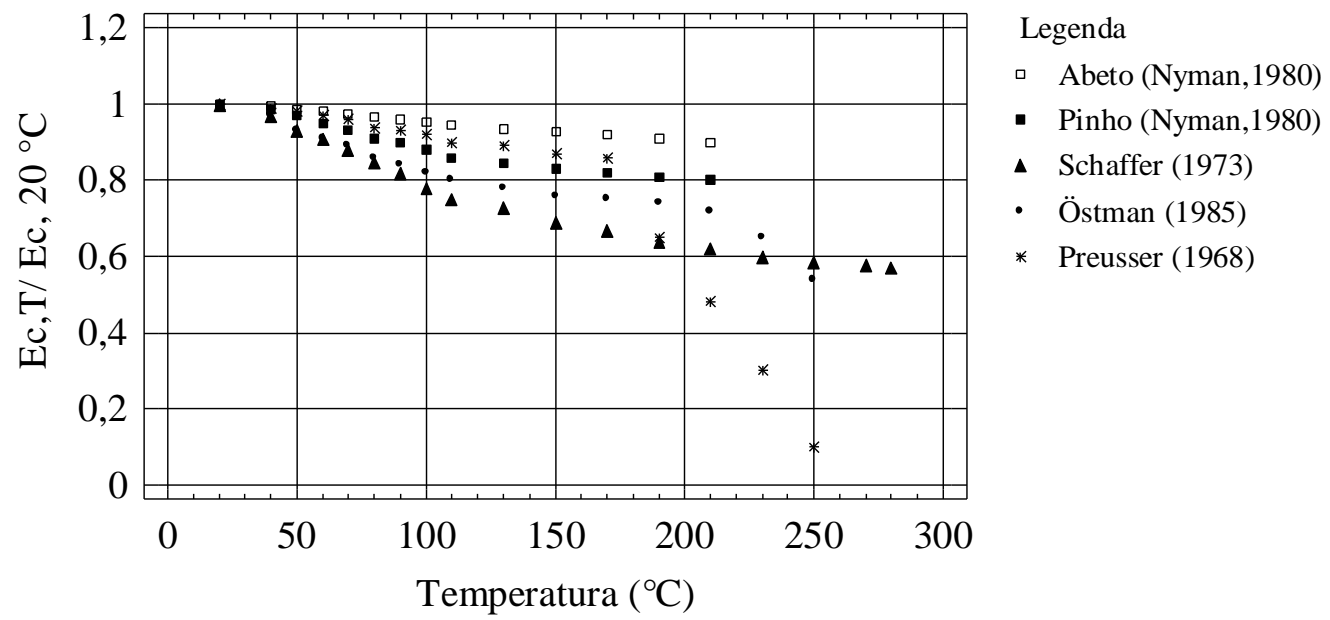

Fonte: Gerhards (1982)

Figura 10 - Módulo de elasticidade à compressão relativo 


\section{Módulo de elasticidade na flexão}

A Figura 11 apresenta valores médios do módulo de elasticidade obtidos por Moraes (2003) em ensaios de flexão em três pontos, usando microcorpos-de-prova da espécie Pinus sylvestris de dimensões $0,43 \mathrm{~mm} \times 5,0 \mathrm{~mm} \times 20,0 \mathrm{~mm}$. Entre $25{ }^{\circ} \mathrm{C}$ e $100{ }^{\circ} \mathrm{C}$, percebe-se que os valores obtidos são superiores àqueles obtidos à temperatura ambiente. Isso pode ser atribuído à redução do teor de umidade dos corpos-de-prova durante a realização do ensaio devido às dimensões reduzidas deles, refletindo no aumento do módulo de elasticidade.

\section{Discussão}

A revisão bibliográfica efetuada mostra que a temperatura e o teor de umidade influenciam de forma inversa as propriedades mecânicas da madeira. Segundo Chafe (1979), a redução da resistência da madeira em função da temperatura tem relação com a degradação térmica de seus componentes e a formação de fendas internas durante o processo de secagem dela.

A influência da temperatura sobre as propriedades mecânicas indica a necessidade de se considerar um fator de redução da resistência para estruturas expostas ao calor prolongado, seja ele oriundo de fatores climáticos ou de uma situação de incêndio. Verifica-se que, para temperaturas próximas a 60 ${ }^{\circ} \mathrm{C}$, algumas propriedades exibem redução de aproximadamente $25 \%$ em relação ao valor apresentado a $20{ }^{\circ} \mathrm{C}$. A norma americana NDS (1997) prevê a utilização de um fator de segurança relacionado à influência da temperatura nas propriedades mecânicas da madeira em função do teor de umidade, que pode chegar a 0,5 para madeiras úmidas e submetidas a temperaturas entre $52{ }^{\circ} \mathrm{C}$ e $65^{\circ} \mathrm{C}$, conforme ilustrado na Fonte: NDS (1997)

Tabela 3. A norma brasileira NBR 7190 (1997) não apresenta esse fator. Portanto, caberá ao comitê responsável pela revisão da referida norma indicar o uso desse valor, após estudos mais detalhados para as madeiras brasileiras.

\section{Conclusões}

Este trabalho apresenta uma revisão bibliográfica abrangente sobre o comportamento da madeira em situação de incêndio, na qual são discutidos assuntos como degradação térmica, taxas de carbonização, influência da temperatura sobre os polímeros da madeira e influência da temperatura sobre as propriedades mecânicas da madeira.

Esta pesquisa leva às seguintes conclusões:

(a) o conhecimento do comportamento da madeira submetida a temperaturas elevadas permite o desenvolvimento de modelos numéricos avançados para a modelagem do comportamento das estruturas de madeira em situação de incêndio;

(b) a madeira, quando exposta ao calor, apresenta a degradação térmica de seus polímeros, a redução de suas propriedades mecânicas e a carbonização de sua superfície;

(c) as taxas de carbonização das madeiras variam conforme a massa específica, o teor de umidade, a espécie de madeira, as dimensões da peças de madeira, a forma da seção transversal e a intensidade do fluxo de calor. Em geral, situam-se entre 0,37 e $0,80 \mathrm{~mm} / \mathrm{min}$. Os valores próximos a 0,37 são para madeiras mais densas e teores de umidade mais elevados, enquanto os próximos a $0,80 \mathrm{~mm} / \mathrm{min}$ são para madeiras secas e com baixa massa específica. Os valores mais recomendados para o projeto de estruturas de madeira laminada colada (MLC) são próximos a 0,65 mm/min; e

(d) a redução das propriedades mecânicas em função da temperatura indica a necessidade de empregar um fator redutor das propriedades obtidas à temperatura ambiente. 


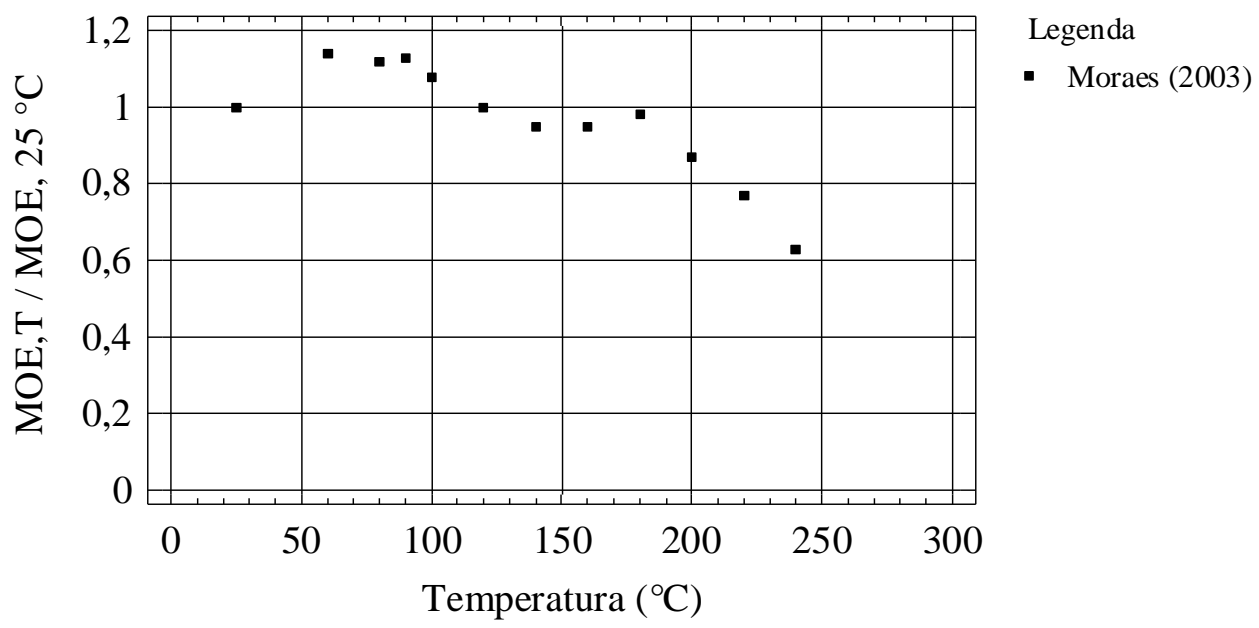

Fonte: Moraes (2003)

Figura 11 - Módulo de elasticidade na flexão relativo

\begin{tabular}{c|c|c|c}
\hline \multirow{2}{*}{ Resistência } & \multirow{2}{*}{ Condições em uso } & \multicolumn{2}{|c}{ Temperatura permanente } \\
\cline { 3 - 4 } & & $\mathbf{3 7}^{\mathbf{}} \mathbf{C}<\mathbf{T} \leq \mathbf{5 2}^{\mathbf{}} \mathbf{C}$ & $\mathbf{5 2}^{\mathbf{0}} \mathbf{C}<\mathbf{T} \leq \mathbf{6 5}^{\mathbf{}} \mathbf{C}$ \\
\hline EI, E E5 $\mathrm{I}, \mathrm{EA}$ & Seca ou úmida & 0,9 & 0,9 \\
\hline Outras propriedades e & Seca & 0,8 & 0,7 \\
\cline { 2 - 4 } ligações & Úmida & 0,7 & 0,5 \\
\hline
\end{tabular}

Fonte: NDS (1997)

Tabela 3 - Fator de redução das propriedades mecânicas devido à temperatura

\section{Referências bibliográficas}

ALÉ, R.; KOTILAINEN, R.; ZAMAN, A. Thermochemical Behavior of Norway Spruce (Picea abies) at $180-225^{\circ} \mathrm{C}$. Wood Science and Technology, Nova York, v. 36, n.1, p. 71-163, 2002.

ALFTHAN, E.; RUVO, A. de; BROWN, W. Polymer, Oxford, v. 14, n. 7, p. 329, 1973.

AMERICAN SOCIETY FOR TESTING AND MATERIALS. E119-08a: fire tests of building construction and materials. Philadelfia, 2009. 31p.

\section{ASSOCIAÇÃO BRASILEIRA DE NORMAS} TÉCNICAS. NBR 7190: projeto de estruturas de madeira. Rio de Janeiro, 1997.

\section{ATREYA, A. Pyrolysis, Ignition, and Flame} Spread on Horizontal Surfaces of Wood. Tese (Doutorado) - Harvard University, Cambridge, 1983.

BABRAUSKAS, V. Ignition of Wood: a review of the State of the Art. In: INTERFLAM 2001, 9., 2001, Edinburgo. Proceedings... Edinburgo: Interscience Communications, 2001. p. 71-88
BABRAUSKAS, V. Wood Char Depth: interpretation in fire investigations. In: INTERNATIONAL SYMPOSIUM ON FIRE INVESTIGATION, Moreton in Marsh, UK, 2004.

BACK, E. L.; SALMÉN, N. L. Glass Transition of Wood Components Hold Implications for Molding and Pulping Processes. Tappi Journal, Norgross, EUA, v. 65, n. 7, p. 107-110, 1982

BHUIYAN, R. T; HIRAI, N.; SOBUE, N. Changes of Crystallinity in Wood Cellulose by Heat Treatment Under Dried and Moist Conditions. Journal of Wood Science, Tokio, v. 46, n. 6, p. 431-436, 2000.

BODÎRLĂU, R.; SPIRIDON, I.; TEACĂ, C. A. Chemical Investigation of Wood Tree Species in Temperate Forest in East-northern Romania. BioResources, Raleigh, EUA, v. 2, n. 1, p. 41-57, 2007.

BODIG, J; JAYNE, B. A. Mechanics of Wood and Wood Composities. $2^{\text {nd }}$. Malabar: Krieger Publishing Company, 1993. p. 712. 
BROWNE, F. L. Theories of the Combustion of Wood and its Control. Madison: Forest Products Laboratory, 1958. 69 p.

BRYDEN, K. M. Computational Modeling of Wood Combustion. Tese (Doutorado) University of Wisconsin-Madison, Madison, USA, 1998.

BUCHANAN, A.H. Structural Design for Fire Safety. Nova Zelândia: John Wiley \& Sons, 2001.

CHAFE, S.C. Growth Stresses in Trees.

Australian Forest Research, Camberra, v. 9, p. 203-223, 1979.

COLLIER, P. C. R. Charring Rates of Timber. Branz, Nova Zelândia: Study Report, 1992.

DRYSDALE, D. Introduction to Fire Dynamics. 2nd. John Wiley and Sons: [S.I.], 1998. p. 451.

\section{EUROPEAN STANDARD EUROCODE.}

Eurocode 5: design of timber structures, part 1-2: general rules-structural fire design. European Committee for standardization, Brusselas, 2002.

FENGEL, D.; WEGENER, G. Wood Chemistry, Ultra Structure, Reactions. Berlim, Walter de Gruyter Publisher, 1984.

FENGEL, D. Uber die Veranderungen des Holzes und Seiner Komponemtem im Temperaturberiech bis $200{ }^{\circ} \mathrm{C}$. Holz Roh-Werkstoff, Nova York, v. 25, n. 2, p. 102-111, 1967.

GERHARDS, C. C. Effect of the Moisture Content and Temperature on the Mechanical Properties of Wood: an analysis of immediate effects. Wood and Fiber, Hannover, v. 14, n. 1, p. 4-36, 1982.

GORING, D. A. I. Thermal Softening of Lignin, Hemicelulose and Cellulose. Pulp and Paper Magazine of Canada, Toronto, v. 64, n. 12, p. 517-527, 1963

GREEN, D. W.; WINANDY, J. E.;

KRETSCHMANN, D. E. Mechanical Properties of Wood. In: DIETENBERGER, M. A. et al. Wood Handbook Wood as an Engineering Material. Madison, Forest Products Laboratory, 1999. p. 145.

HATAKEYAMA, H.; HATAKEYAMA, T.; NAKANO. DSC Study on Recrystallization of Amorphous Cellulose With Water. Journal Cellulose Chemical and Technology, Bucareste, v. 18, n. 2, p. 495, 1974.
IRVINE, G. The Glass Transitions of Lignin and Hemicellulose and Their Measurement by Differential Thermal Analysis. Journal Tappi, Norgross, EUA, v. 67, n. 5, p. 116-121, 1984.

\section{INSTITUTO NACIONAL DE}

NORMALIZACIÓN. NCh 979: determinación de las propiedades mecánicas, ensayo de extracción de clavos. Santiago, 1986. 7 p.

\section{INTERNATIONAL ORGANIZATION FOR} STANDARDIZATION. ISO 834. Fire-resistence tests - Elements of building construction, 1975. $16 \mathrm{p}$.

KNUDSON, R. M.; SCHNIEWIND, A. P. Performance of Structural Wood Members Exposed to Fire. Forest Products Journal, Madison, v. 25, n. 2, p. 23-32, 1975.

KOLLMANN, F. F. P. e COTE, W. A. Jr. Principles of wood Science and Technology. In: Solid wood. Springer, Berlin Heidelberg New York, 1968. p592.

KOTILAINEN, R. Chemical Changes in Wood During Heating at 150-260 1C. Tese (Doutorado em Química) - Jyväskylä University, Finlândia; 2000.

LANDESMANN, A. et al. Análise TermoMecânica de Estruturas de Madeira Submetidas a Altas Temperaturas: materiais, métodos e modelos numéricos. Relatório de Pesquisa. Departamento de Engenharia Civil Centro Tecnológico, Universidade Federal de Santa Catarina, 2008.

LAU, P. W.; BARRETT, J. D. Modeling Tension Strength Behaviour of Structural Lumber Exposed to Elevated Temperatures. In: INTERNATIONAL SYMPOSIUM ON THE FIRE SAFETY SCIENCE, 5., Melbourne, 1979. Proceedings... Melbourne, 1979. p. 1177-1188.

LEVAN, S. L. Thermal Degradation. In: SCHNIEWIND, A. P. (Ed.): Concise Encyclopedia of Wood \& Wood-Based Materials Exeter. Elmsford, NY: Pergamon, 1989. p. 271-273.

LIE, T.T. A Method for Assessing the Fire Resistance of Laminated Timber Beams and Columns. Canadian Journal Civil Engineering, Vancouver, v. 4, p. 161-169, 1977. 
MANGALAM, A. Electroheating Novel Process for Modifying Wood. Dissertação (Mestrado) College of Graduate Studies, University of Idaho, Moscow, 2005.

MANNINEN, A. M; PASANEN, P.; HOLOPAINEN, J. Comparing the VOC Emissions Between Air-Dried and Heat-treated Scots Pine Wood. Atmospheric Environment, Oxford, v. 36, n. 11, p. 1763-1768, 2002.

MANRIQUEZ, M. J. Influência da Temperatura sobre as Propriedades Mecânicas do Paricá. Dissertação (Mestrado em Engenharia Civil) Escola de Engenharia, Universidade Federal de Santa Catarina, Florianópolis, 2008.

MILLER, R. S.; BELLAN, J. A Generalized Biomass Pyrolysis Model Based on Superimposed Cellulose, Hemicellulose and Lingnin Kinetics. Combustion Science and Technology, v. 126, p. 97-137, 1996.

MIKKOLA, E. Charring of Wood. Espoo: Technical Research Center of Finland, 1990.

MORAES, P. D. Influence de la Temperature sur les Assemblages Bois. Tese (Doutorado) Université Henri Poincaré, Nancy 1, 2003.

MORAES, P. D.; ROGAUME, Y.; TRIBOULOT, $\mathrm{P}$. Influence of Temperature on the Embedding Strength. Holz als Roh-und Werkstoff, v. 63, p. 297-302, 2005.

\section{NATIONAL DESIGN SPECIFICATION. NDS} for Wood Construction. Washington: American Forest and Paper Association, 1997. p. 10-158.

NJANKOUO, J. M.; DOTREPPE, J. C.; FRANSSEN, J. M. Experimental Study of the Charring Rate of Tropical Hardwoods. Fire and Materials, v. 28, p. 15-24, 2004.

NYMAN, C. The Effect of Temperature and Moisture on the Strength of Wood and Gluelines. Espoo: Forest Products Laboratory, 1980. (Report n. 6)

OHSAWA, J.; YONEDA, Y. Shear Test of Woods as a Model of Defibration. Journal of the Japanese Wood Research Society, v. 24, n. 4, p. 230-236, 1978.

OLSSON, A. M.; SALMÉN, L. Humidity and temperature affecting hemicellulose softening in wood. In: International conference of coast action E8. Denmark, pp269-279, 1997.
OSTMAN, B. A. Wood Tensile Strength at Temperature and Moisture Contents Simulating Fire Conditions. Wood Science and Technology, v. 19, p. 103-116, 1985.

PESCADOR, W.; MANRÍQUEZ, M.; MORAES, P. D. Influência da Temperatura sobre a Resistência ao Arrancamento do Paricá. In: ENCONTRO BRASILEIRO EM MADEIRA E ESTRUTURAS DE MADEIRA, 11., Londrina, 2008. Anais... Londrina, 2008.

PINTO, M. E. Determinação de um Modelo de Taxa de Carbonização Transversal a Grã para o Eucalyptus Citriodora e Eucalyptus Grandis. Tese (Doutorado em Engenharia) - Escola de Engenharia, Universidade de São Paulo, São Carlos, 2005.

PONCSÁK, S. et al. Effect of High Temperature Treatment on the Mechanical Properties of Birch (Betula papyrifera). Wood Science and Technology, v. 40, n. 8, p. 647-663, 2006.

PREUSSER, R. Plastic and Elastic Behaviour of Wood Affected by Heat in Open Systems. Holz technologie, v. 9, n. 4, p. 229-231, 1968.

ROFFAEL, R; SCHALLER, K. Einfluss Thermischer Behandlung auf Cellulose. Holz Roh-Werkst, v. 29, p. 275-278, 1971.

SALMÉN, N. L. Thermal Softening of the Components of Paper, its Effect on Mechanical Properties. Trans. Technology. v. 5, n. 3, p. 45-50, 1979.

SALMÉN, L. Temperature and Water Induced Softening Behaviour of Wood Fiber Based Material. Tese (Dissertação) - Department of Paper Technology, The Royal Institute of Technology, Estocolmo, 1982.

SANO, E. Effects of Temperature on the Mechanical Properties of Wood: I. Compression parallel to grain. II. Tension parallel to grain. III. Torsion test, Journal of the Japanese Wood Research Society, v. 7, n. 4, p. 147-150, 1961.

SARDINHA, A. M; WOLFANGO, M.; VASCONCELOS, F. M. Combustão Lenhosa Direta e Indireta Sua Relevância para a Temática dos Fogos Florestais. Silva Lusitana, Lisboa, v. 10, n. 1, p. 91-100, EFN, 2002.

SCHAFFER, E. L. Charring Rate of Selected Woods-Transverse to Grain. Madison: Forest Products Laboratory, 1967. 
SCHAFFER, E. L. Effect of Pyrolytic

Temperatures on the Longitudinal Strenght of Dry Douglas Fir. Journal of Testing and Evaluation, v. 1, n. 4, p319-329, 1973.

SCHAFFER, E. L. Strength Validation and Fire Endurane of Glued Laminate Timber Beams.

Madison: Forest Products Laboratory, 1986.

SCHNIEWIND, A. P. Concise Encyclopedia of Wood and Wood-Based Materials. Nova York: Pergamon Press, 1985. p. 271-273.

SHAFIZADEH, F. Pyrolytic Reactions and Products of Biomass. In: OVEREND, P. P. Nova York: Elsevier, 1985. p. 183-217.

SIVONEN, H. et al. Magnetic Resonance Studies of Thermally Modified Wood. Holzforschung, v. 56, n. 6, p. 648-653, 2002.

SZÜCS, C. A. et. al. Proposta em Ensaios para Cisalhamento Paralelo às Fibras da Madeira. In: ENCONTRO BRASILEIRO EM MADEIRA E ESTRUTURAS DE MADEIRA, 6., 1998, Florianópolis. Anais... Florianópolis, 1998.

YANO, S., HATAKEYAMA, H.;

HATAKEYAMA, T. J. Effect of Hydrogen Bond Formation on Dynamic Mechanical Properties of Amorphous Cellulose. Journal Applied Polymeric Science, v. 20, n. 12, p. 3221-3231, 1976.

YILDIZ, S.; GÜMÜSKAYA, E. The Effects of Thermal Modification on Crystalline Structure of Cellulose in Softwood and Hardwood. Building and Environment, v. 42, n. 1, p. 62-67, 2007.
WHITE, R. H. Charring Rates of Different Wood Species. Tese (Doutorado) - University of Wisconsin, Madison, 1988.

WHITE, R. H. Fire Endurance Research Forest Products Technologist. Madison: Forest Products Laboratory, 1990.

WHITE, R. H. Analytical Methods for Determining Fire Resistance of Timber Members. 3th. Westford: society of Fire Protection, 2002. cap. 11.

WHITE, R. H. Fire Resistance of Structural Composite Lumber Products. Madison: Forest Products Laboratory, 2006.

WIKBERG, H.; MAUNU, S. L. Characterization of Thermally Modified Hard- and Softwoods by 13C CPMAS NMR. Carbohydrate Polymers, v. 58, p. 461-466, 2004.

WINANDY, J. E.; ROWELL, R. M. The Chemistry of Wood Strength. In: ROWELL, R. M. Handbook of Wood Chemistry and Wood Composites. Boca Raton: Taylor and Francis, 2005

ZERONIAN, S. H.; MENEFEE, E. ThermallyInduced Changes in the Mechanical Properties of Ramie and Chemically-Modified Ramie. Journal Applied Polymer Science, v. 28, p. 869, 1976.

\section{Agradecimentos}

Os autores agradecem à Coordenação de Aperfeiçoamento de Pessoal de Nível Superior (CAPES), Brasil, e à Fundação para a Ciência e Tecnologia (FCT), Portugal, pelo apoio a esta pesquisa. 